\title{
What should be done about hepatitis-B-infected health-care workers?
}

In 1993, the Department of Health of England and Wales introduced strict guidelines, updated in 1998, in an attempt to prevent health-care worker (HCW)-topatient transmission of hepatitis $B$ virus (HBV) infection in the UK (Department of Health, 1993, 1998). Thus, hepatitis B e antigen (HBeAg)-positive HCW were not allowed to practice exposure-prone procedures (EPP) because of their assumed high virus load and the associated risk of transmission. However, it is now common knowledge that hepatitis B surface antigen (HBsAg)-positive carriers who have antibodies to $\mathrm{HBeAg}$ (i.e. anti-HBepositive) may also have high levels of $\mathrm{HBV}$ DNA. Their viruses often have variants of the pre-core region of the genome that are believed to prohibit $\mathrm{HBeAg}$ production (Carman et al., 1989). The range of HBV DNA levels in anti-HBe-positive carriers is wide and overlaps the generally higher levels associated with HBeAg. HBV DNA levels between $10^{4}$ and $10^{6}$ genomes $\mathrm{ml}^{-1}$ can be found in either HBeAg- or anti$\mathrm{HBe}$-positive persons (Martinot-Peignoux et al., 2002). Anti-HBe-positive HCW with HBV DNA levels from just below $10^{5}$ genomes $\mathrm{ml}^{-1}$ upwards have been proven to transmit $\mathrm{HBV}$ to patients during a variety of EPP; usually gynaecological, general or cardiothoracic surgery (Heptonstall et al., 1997). Based on the known virus loads of those HCW and the evidence that viraemia levels can fluctuate by a log in either direction over time, the Advisory Group on Hepatitis in the UK, a formally constituted committee of the Departments of Health of England and Wales, recommended that all HCW with a viraemia above $1 \times 10^{3}$ genomes $\mathrm{ml}^{-1}$ should not be allowed to perform EPP (Departments of Health, 2000). It stipulated that all HBsAg-positive, anti$\mathrm{HBe}$-positive HCWs wishing to continue to practice EPPs must send two separate serum samples, taken a week apart (to obviate handling errors and to measure any short-term fluctuation in level), for determination of HBV DNA level in each of two laboratories, Glasgow and Birmingham. We believe that all known HBsAg-positive HCWs performing EPP in the UK at the time of issuance of this guideline have now been tested. Overall, $42 \%$ of these HCW were allowed to continue EPP based on their low HBV DNA level. Those HCWs excluded from EPP practice may be allowed back after antiviral therapy, but only if their HBV DNA level remains below $10^{3}$ genomes $\mathrm{ml}^{-1}$ for at least a year after cessation of treatment. However, even at that stage, readmission is not automatic; the HCW must apply to the Department of Health to be allowed to restart EPP. Here, we review the guidelines and ask if they should be modified.

\section{Has the virus load been set correctly?}

There are some good data that virus load can fluctuate in chronic carriers (R. S. Tedder and others, personal communication), but other data indicating that levels remain remarkably stable (Lindh et al., 2000). Consequently, it is possible that a person who currently has $10^{4}$ genomes $\mathrm{ml}^{-1}$ could have $10^{5}$ genomes $\mathrm{ml}^{-1}$ at some stage over the post-testing 12month period and thus be at risk of transmission. It is because of this known fluctuation, and the knowledge that all but one transmissions have occurred in persons with more than $10^{5}$ genomes $\mathrm{ml}^{-1}$, that the cut-off was set at $10^{3}$. However, it has transpired that $22 \%$ of all anti-HBepositive HCW have been excluded because they had a virus load between $10^{3}$ and $10^{4}$ genomes $\mathrm{ml}^{-1}$ (unpublished data). In the Netherlands, a level of $10^{5}$ genomes $\mathrm{ml}^{-1}$ has been set, for two reasons. Firstly, they were not keen to exclude such a high proportion of EPP workers. Secondly, they felt that there are two relatively distinct populations of HBV DNA levels and that it is unlikely that individuals will migrate between them (H. Zaaijer, personal communication). However, testing of HCW in the UK did not reveal two clear peaks. Clearly, there is an issue of pragmatism versus caution: the aim of the Departments in the UK was to reduce the risk of future transmissions as much as was reasonably possible.

\section{Should the skill and experience of the operator be taken into consideration?}

These authors do not know whether the transmissions so far were from experienced or from relatively inexperienced practitioners. If they were all in the latter group, one might suggest resetting a higher DNA level whilst instituting strict training and ongoing education for those persons doing EPP with a detectable virus load up to the new level. These persons could be supervised by a 'guardian angel' until they were considered to be practising sufficiently carefully to minimize the transmission risk. The problem with such an approach is that it is difficult to institute and to monitor. Certainly, leaving it at the current level is a simpler approach, reducing the risk to nearly zero.

\section{Would better enforcement of reporting of any injuries sustained during surgery allow early follow-up?}

Perhaps better enforcement would allow early follow-up of potentially infected patients and institution of appropriate prophylaxis or antiviral therapy. This approach is linked to suggestions that infected HCW should be allowed to tell patients their HBV status and allow them to decide whether they wish to continue with the procedure.

\section{Should the guideline apply to all EPP workers?}

The type of procedure associated with transmission has consistently been major surgery. However, no evidence is available to allow the definition of a set of EPPs that are deemed of such low risk of HCWpatient transmission that the guidelines can be relaxed for those procedures.

\section{Should HCWs be allowed to practice EPP whilst on antiviral therapy?}

There are a number of effective anti-HBV drugs licensed or in late-stage clinical testing (for a review, see Liaw, 2002). All of these agents reduce virus load effectively, but DNA levels may rebound when therapy is 
stopped. This clearly raises a problem with the current guidance, whereby a return to work is conditional upon DNA levels remaining low for a year after therapy is withdrawn. Most published data refer to lamivudine therapy. Resistance to lamivudine develops at an alarming rate; some $60 \%$ of treated persons have resistance mutations, with detectable viraemia, within 3 years (Liaw et al., 2000). Consequently, any person allowed to practice whilst still on nucleoside analogue therapy would need regular monitoring both clinically and by virus load measurements to ensure continued compliance with therapy and that resistance mutations did not develop, at least not with high attendant viraemia. However, there is some evidence that the virus load associated with the emergence of drug-resistant mutants is not as high as that prevailing prior to initiation of therapy (Lai et al., 1998). Viruses carrying resistance mutations are not as replication-competent as wild-type (Melegari et al., 1998), and it is therefore possible that they are not as transmissible. In addition, data on development of resistance are derived largely from patients with high initial virus loads, and it is likely that those who have lower pre-treatment virus loads (between $10^{3}$ and $10^{4}$ genomes $\mathrm{ml}^{-1}$ ) will be much slower to develop resistance mutations. The licensing of newer antivirals such as adefovir, resistance to which is extremely unusual (Peters et al., 2002), make it even more attractive to adopt a policy allowing anti-HBe-positive HBV-carrier HCWs back to EPPs whilst on therapy. Interestingly, if this eventuates, this will create a new indication for therapy; i.e. in order to allow continuation of professional practice. Although it is unlikely that any of the drugs will be licensed for this use, they could still be used if a clinician so desired. It goes without saying that the HCW has to agree to being treated!

\section{Should testing still be done in two laboratories, or could any accredited laboratory with sufficient experience in HBV DNA measurement be allowed to do the assay?}

Although we believe that the taking of two samples a week apart is essential (to avoid laboratory and clinical errors), the interlaboratory and inter-assay variability has been so low in the pilot programme that now only one of the two laboratories need test samples from each HCW. If other laboratories do participate in this activity, results should be collated centrally in order to monitor progress with the system and any problems that might appear. If so, it would be crucial that the control serum set at $10^{3}$, manufactured by the Birmingham laboratory, should be used to avoid inconsistencies, as a number of samples have been at the cut-off level. However, on balance, as the numbers being tested are much lower than in the initial year, we would suggest that samples still be tested in the two designated laboratories. This is a potentially litigious area, possibly best avoided by most labs.

\section{What has happened to the $\mathbf{1 0 0}$ or so HCWs who have been barred from performing EPPs?}

This is unclear: have they been retrained? Are they still practising in the UK? Have they moved to other specialities? A study to address these issues is under way.

\section{Conclusions}

The very real problem of transmission of HBV from anti-HBe-positive HCWs has been addressed using a 'near-zerotolerance' approach in the UK and there have been few problems with its implementation. However, we believe it is time to reassess both the level and the policy of allowing persons to be on treatment while practising EPP. In a step towards this, a European consensus meeting was convened in October 2002 to try to agree guidelines that will suit most European countries; these will be published in Journal of Clinical Virology, the official journal of the PanAmerican and European Societies for Clinical Virology, in 2003.

\section{Acknowledgements}

The West of Scotland Specialist Virology Laboratory is a member of the UK Clinical Virology Network (www.clinical-virology.org).

\section{William F. Carman and Sheila 0. Cameron}

West of Scotland Specialist Virology Laboratory, Gartnavel General Hospital, PO Box 16766, Glasgow G12 OZA, UK

Correspondence: William F. Carman (ann.smith@northglasgow.scot.nhs.uk)
Carman, W. F., Jacyna, M. R., Hadziyannis, S., Karayiannis, P., McGarvey, M. J., Makris, A. \& Thomas, H. C. (1989). Mutation preventing formation of hepatitis $B$ e antigen in patients with chronic hepatitis B infection. Lancet ii, 588-591.

Department of Health (1993). Protecting health care workers and patients from hepatitis $B$. Health Service Guidelines HSG (93) 40. London: Department of Health.

Department of Health (1998). Guidance for clinical health care workers: protection against infection with blood-borne viruses. Health Service Circular HSC (1998)/063. London: Department of Health.

Department of Health (2000). Hepatitis B infected health care workers. Health Service Circular HSC (2000)/02. London: Department of Health.

Hadziyannis, S. J., Tassopoulos, N. C., Heathcote, E. J. \& 10 other authors (2003). Adefovir dipivoxil for the treatment of hepatitis B e antigen-negative chronic hepatitis B. N Engl J Med Med 348, 800-807.

Heptonstall, J., Barnes, J., Burton, E. \& 25 other authors (1997). Transmission of hepatitis B from four infected surgeons without hepatitis B e antigen. The Incident Investigation Teams and others. N Engl J Med 336, 178-184.

Lai, C. L., Chien, R. N. \& Leung, N. W. \& 9 other authors (1998). A one-year trial of lamivudine for chronic hepatitis B. Asia Hepatitis Lamivudine Study Group. N Engl J Med 339, 61-68.

Liaw, Y.-F. (2002). Therapy of chronic hepatitis B: current challenges and opportunities. J Viral Hepat 9, 393-399.

Liaw, Y.-F., Leung, N. W. Y., Chang, T. T. \& 8 other authors (2000). Effects of extended lamivudine therapy in Asian patients with chronic hepatitis B. Asia Hepatitis Lamivudine Study Group. Gastroenterology 119, 172-180.

Lindh, M., Horal, P., Dhillon, A. P. \& Norkrans, G. (2000). Hepatitis B virus DNA levels, precore mutations, genotypes and histological activity in chronic hepatitis B. J Viral Hepat 7, 258-267.

Martinot-Peignoux, M., Boyer, N., Colombat, M. \& 7 other authors (2002). Serum hepatitis $B$ virus DNA levels and liver histology in inactive HBsAg carriers. J Hepatol 36, 543-546.

Melegari, M., Scaglioni, P. P. \& Wands, J. R. (1998). Hepatitis B virus mutants associated with 3TC and famciclovir administration are replication defective. Hepatology 27, 628-633. 